\title{
Water Transportation Workers
}

National Cancer Institute

\section{Source}

National Cancer Institute. Water Transportation Workers. NCI Thesaurus. Code

C122532.

Workers in water transportation occupations who operate and maintain vessels that take cargo and people over water. 